\title{
La moral y su evolución
}

\author{
Morality and its Evolution
}

Eduardo Vázquez-Domínguez1.., María del Pilar Gómez Ortiz²

\begin{abstract}
:
The moral arises with the need to dictate rules of behavior that allow harmonious coexistence among men, although from the beginning these rules have been established by force or power, however, to be part of the awareness of man, it opposes or reaffirms the moral principles that it considers pertinent, at the same time it is demanding its transformation based on social, educational, economic and international influence development.
\end{abstract}

\section{Keywords:}

Morality, Ethics, Values, Transmutation

\section{Resumen:}

La moral surge con la necesidad de dictar normas de comportamiento que permitan la convivencia armónica entre los hombres, aunque desde su origen estas normas han sido establecidas a través de la fuerza o el poder, sin embargo, al formar parte de la conciencia del hombre, esté va oponiéndose o reafirmando los principios morales que considera pertinente, al mismo tiempo va exigiendo su transformación en base al desarrollo social, educativo, económico y de influencia internacional.

\section{Palabras Clave:}

Moral, Ética, Valores, Transmutación

\section{Introducción}

La presente reseña tiene como objetivo plantear el origen de la moral y su diferencia con respecto a la ética, así como clarificar la forma en la que

\footnotetext{
${ }^{1}$ Profesor en el Programa Bachillerato General, Escuela Superior de Tepeji del Rio, Av. Del Maestro No. 41 Colonia Noxtongo 2 a Sección, Tepeji del Rio, Hidalgo, México. Correo: evd 2000@yahoo.com.mx

2 Profesora en el Programa Bachillerato General, Escuela Superior de Tepeji del Rio, Av. Del Maestro No. 41 Colonia Noxtongo

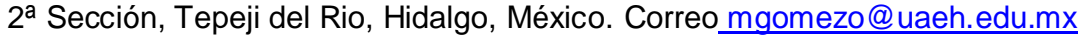


los principios morales se van transformando para dar respuesta a las necesidades de una nueva visión de convivencia armónica, acorde a avances en la concepción de derechos humanos, entre los que destaca una nueva visión de lo que es la libertar, la equidad de género, el derecho igualitario, y los aportes que descubrimientos científicos y tecnológicos han realizado y que lo llevan a tener una visión distinta de su entorno y consecuentemente de la forma de adecuar sus principios morales, lo que al final se traduce en una forma distinta de desarrollar la convivencia humana.

Todos estos procesos evolutivos conllevan a la transformación de formas de pensar desde la perspectiva de directrices morales, cambios que para un alto porcentaje de la población implican un retroceso en las buenas costumbres y en el desarrollo cotidiano de la vida moral de todos los integrantes de la sociedad, aunque, para la mayoría implica adecuar los principios morales a las necesidades y exigencias de un mundo cada vez más globalizado.

\section{Antecedentes de la moral}

Muchos son los tratadistas que han escrito sobre el origen de la moral, algunos lo encuentran en dos corrientes, una que considera que la moralidad es una innovación cultural propia del ser humano. No considera la moral como propia de la naturaleza humana. Thomas Henry mencionado por Molina (2013) señala "La moralidad es un revestimiento cultural, una fina capa que oculta una naturaleza egoísta y brutal", la otra corriente sostiene que es parte del instinto social que son comunes a otros animales, en otras palabras, es el resultado de la evolución social. (Molina, 2013).

Para referirnos con más objetividad al origen de los principios morales señalaremos que surgen, de acuerdo a Escobar (2013) con la aparición del ser humano ya que dentro de su misma naturaleza está implícita la necesidad del establecimiento de normas de conducta que han permitido una convivencia armónica, así es como este autor reconoce cuatro momentos evolutivos de la moral, el primero es la moral primitiva en donde impera una moral de ayuda mutua que se traduce en colectivismo (obtención de alimentos, protección, construcción, etc.) y que estaba muy relacionada con la religión. La segunda es la moral en la Antigüedad Clásica etapa que se caracterizó por la aparición de la esclavitud y la propiedad privada, si mismo la mujer es menospreciada por ser considerada inferior, filósofos como Platón señalaban que la moral solo era ejercida por los hombres libres, por cierto en referencia a Platón se le señala como el creador de la corriente denominada Intelectualismo Moral (Abad, 2009), por su parte Aristóteles se niega a aceptar que los esclavos fueran hombre y que las mujeres libres fueran un miembro de la sociedad con igualdad de derechos. La tercera etapa es la moral en la sociedad feudal, aquí la moral que domina es la propagada por la aristocracia, etapa en la que se reconoce a los ciervos (antes esclavos) como seres humanos, las principales virtudes eran: el honor, el valor, el arte de la guerra y la nobleza de sangre, algo muy 
importante es la subordinación a la religión quien era la suprema legisladora de la moral, en donde imperaba un supremo fin ultraterrestre. Por último, tenemos la moral en la sociedad moderna, esta época es caracterizada por el afán en la búsqueda de riqueza lo que repercutió necesariamente en los principios morales, la ciencia también ha jugado un papel trascendental en el cambio de la mentalidad humana, lo que ha permitido dejar atrás la noción implantada por la iglesia de tener un origen del pecado original. Los valores más destacados de esta época son la honradez, la laboriosidad, el patriotismo, la felicidad conyugal, el ahorro y la astucia. La curiosidad intelectual y la confianza en sí mismo pasó de pecado mortal a virtud sobresaliente, otra característica de esta época es el individualismo exacerbado que se traduce en una ética utilitarista.

Otro aspecto importante al estudiar las bases de la moral es analizar el valor moral, que de acuerdo a Gutiérrez (1998) el valor moral tiene dos aspectos uno material y otro formal, el primero lo define como "La adecuación entre un acto y las exigencias de la naturaleza racional y libre del que lo ejecuta" ( $p$ 109), esto implica que una persona actúa bien cuando actúa libre y racionalmente conforme a las exigencias de su misma naturaleza humana, así por ejemplo el matar no es bueno, porque contraviene la exigencia más íntima de la naturaleza humana que tiende siempre a la vida. Por otro lado, está el aspecto formal del valor moral, que Gutiérrez traduce como la parte espiritual que guía el actuar del hombre en la que se conjuga la razón y la voluntad para auto determinarse y de esa forma conferir valor moral al acto humano.

\section{Significado etimológicos y concepto de moral}

La palabra moral viene del latín mos que significa costumbre, habito lo que se traduce en el conjunto de reglas adquiridas por medio del hábito, de esta misma forma Palacios (2009) describe el significado de la palabra, sin embargo refiere que entonces la moral no acarrea por si el concepto de malo o de bueno, y que por consecuencia son las costumbre las que son virtuosas o perniciosas, por otro lado Ortiz (2016) reconoce el mismo origen latín sin embargo duda de su etimología señalando que posiblemente refiera a medida, y que sería propiamente una regla de vida que mide o guía.

De su significado y aplicación se han dado un sin fin de definiciones entre esta están las siguientes: "Conjunto de normas aceptadas libre y conscientemente, que regulan la conducta individual y social de los hombres". (Escobar, 2013, pág. 125)

"Como una dimensión que pertenece al mundo vital, y que está compuesta de valoraciones, actitudes, normas y costumbres que orientan o regulan el obrar humano". (De Zan, 2004)

"Como conjunto de creencias y normas de una persona o grupo social determinado que ofician de guía para el obrar, es decir, que orientan acerca del bien o del mal -correcto o incorrectode una acción" (Palacios de la Torre, 2009, parr. 4)

De estas definiciones se pueden resaltar elementos esenciales de la moral como son: 
$>$ Normas morales que regulan las acciones de los hombres en una sociedad.

$>$ Se requiere de un hombre en completo uso de su libertad que acata y realiza las normas morales.

$>$ Existencia de valores inherentes a las normas morales.

\section{Diferencia entre moral y ética}

Para dar inicio a esta diferenciación debemos de partir de la ubicación que tiene la moral en el sistema filosófico y que de acuerdo a Escobar (2013) la moral queda ubicada como una diciplina practica, denominada axiologia o Teoria de los Valores, y que en su seno contiene a la ética. (pag 73), y ya hablando de la ética es pertinente señalar que la palabra ética probiene del griego ethos que significa "Teoria o un tratado de los habitos y las costumbres", el primero que usa la palabra fue Homero y la entendia como "lugar habitado por hombres y animales, aun que es Aristoteles quien la define como "habito", "mode de ser" o "carácter". Comparando el significado de esta palabras con el de moral nos damos cuenta que la moral da origen a la etica ya que esta establece y define la forma en la que un conjunto de hombres deben de actuar dentro de una sociedad, y sera la ética quien analice desde un aspecto individual la esencia del acto, por lo que la moral se convierte por ese solo hecho en el objeto de estudio de la ética, en otras palabras de acuerdo a Escobar la "Ética es la diciplina filosofica que estudia el comportamiento moral del hombre en sociedad" ( $p$ 75), considerando estos elementos se pueden estableser caracteristicas particulares tanto de la moral como de la ética, Manrique (2006) reconoce las siguientes:

1. Características de la Moral. Es el conjunto de normas a saber que se transmiten de generación en generación, evolucionan a lo largo del tiempo y poseen fuertes diferencias con respecto a las normas de otra sociedad y de otra época histórica, estas normas se utilizan para orientar la conducta de los integrantes de esa sociedad.

2. Características de la Ética. Es un conjunto de normas principio y razones que un sujeto ha analizado y establecido como una línea directriz de su propia conducta.

De estas características podemos establecer que la moral es práctica ya que define o establece un conjunto de deberes, normas o valores que el hombre debe observar, en cambio la ética es teórica al ser un conjunto de reflexiones teóricas acerca de esas obligaciones normativas, podemos reafirmar los elementos aquí establecidos con lo señalado por Torres (2014, p 13) quien al realizar un contraste entre la ética y la moral destaca que la moral es pratica, se ejecuta y se ejerce, que son un conjunto de normas, que es objetiva y por el otro lado la ética es teorica, contemplativa, abstracta y son un conjunto de reflexiones.

\section{Problemas de la Moral}

\section{Problema de la valoración moral}

Antes de entrar al análisis de algunos de los tantos problemas a los que se enfrenta la 
valoración moral es importante destacar que el establecimiento de las valoraciones éticas o bien del establecimiento de principios morales son dadas por los grupos predominantes ya sea en función de fuerza física como en la época primitiva o en función de poder como sucedió en la época del obscurantismo con la religión católica, o como en la actualidad en donde la presión de un entorno globalizado influye en la modificación de tradiciones, costumbres y valoraciones.

¿Pero que es la valoración moral? Es el hecho de atribuirle o adjudicarle valor a una acción humana determinada, esta acción tiene tres elementos un sujeto que valora, una acción u omisión de valoración y un juicio valorativo.

Pues bien, de esta valoración surge la esencia del problema, principalmente cuanto se parte de establecer, ¿qué es lo bueno? y si esa concepción es aceptada de la misma forma entre todos los grupos sociales, en todos los tiempos y bajo todas las circunstancias, tratando de dar respuesta a esta problemática han surgido teorías sobre qué es lo bueno, dentro de estas se destacan las siguientes:

La Teoría del Hedonismo, establece que lo bueno radica en el placer y la ausencia del dolor, la Teoría del Eudemonismo, señala que lo bueno consiste en el logro de la felicidad como supremo fin de la vida humana, en cambio la Teoría del Formalismo señala que lo bueno es lo incondicionado sin restricción alguna, actuar solo conforma al deber, por su parte la Teoría del Utilitarismo sostiene, el bien estriba en lo útil, en aquello que nos proporciona bienestar, placer y confort, y por último el vitalismo que sostiene que lo bueno se adquiere mediante el máximo desarrollo de los impulsos vitales, la fuerza del poder, la voluntad de dominio. (Escobar, 2013, pág. 83)

\section{Problema de la obligación moral.}

Toda norma moral surge aparejada a un grado de obligatoriedad, ya que de no orillar a su observancia esta no cumpliría su fusión de fungir como una guía de comportamiento humano que garantice una convivencia armónica, en consecuencia es importante establecer de donde surge esta obligatoriedad, pues bien tratadistas como Escobar (2013) señala que existen dos corrientes que explican este dilema, el primero es la heteronomía en donde se afirma que la obligatoriedad deriva de la norma impuesta por una unidad exterior, en otras palabras no surge de la propia voluntad, no obstante es forzada a actuar de acuerdo a lo establecido, la otra corriente es la autónoma aquí señala que la voluntad se determina así misma en la observación del principio moral, aquí cita lo establecido por Kant al momento que esté señala que la decisión que se tome se quiera al mismo tiempo que esta se convierta en una ley universal. En este caso la libertad no implica necesariamente elegir un buen comportamiento sino también la posibilidad de elegir el lado contrario, lo que implicaría que al transformarse en una ley universal también se le aplicaría al sujeto que tomó la decisión; Escobar también señala que esta ética autónoma es la expresión más acabada del hombre moderno.

Otra perspectiva del problema de la valoración moral se da al establecer que la valoración actúa 
en función del agrado o del desagrado o bien de deseos o intereses y que por cierto tanto los deseos e intereses son acciones que producen efectos en el mundo, mismo que son observables y por lo tanto medibles, lo que implica que la valoración no solo tiene una realidad mental sino también una realidad factual, consecuencias que no siempre coinciden con los fines previstos o contemplados en el mundo, por lo que tanto deseos e intereses (y por tanto valoraciones) maduran y se ponen a prueba, lo que se interpreta como el equilibrio o desequilibro de lo que puede prevalecer como valor moral, así mismo se entiende que es esté desequilibrio lo que va produciendo nuevas formas de valoración. (Dewey, 2008), por otro lado, esta disyuntiva entre agrado y desagrado nos lleva a lo que se llama toma de decisiones y que consiste en el proceso mediante el cual un individuo escoge entre dos o más alternativas posibles (Sánchez, 2006), en donde el factor importante está en la voluntad, ya que es ahí donde se selecciona y jerarquizan las características de cada posibilidad, lo que implica una solución continua de conflictos mediante la inhibición de un deseo sobre otro, esta voluntad puede ser evaluada desde el punto de vista ético moral, tanto en su fuerza o debilidad como en su flexibilidad o rigidez, estas últimas características constituyen elementos importantes para la transformación de los valores.

Un ejemplo del problema de la valoración moral lo encontramos en el tema analizado por Duarte y Sanchez (2017) en referencia a como la mentira es útil en un paciente en etapa terminal, en donde reconocen que la mentira es considerada un antivalor, no obstante señalan la necesidad de su existencia para pacientes terminales con el objetivo de producir en ellos un autoengaño que permita al paciente hacerse de herramientas como el optimismo y la esperanza, así mismo señalan que la utilidad de la mentira puede justificarse ya que provoca un beneficio, a diferencias de la verdad que puede ocasionar un mal mayor.

Como hemos podido analizar existen muchas circunstancias y condiciones que hacen que la valoración moral se convierta en un verdadero dilema o bien un conflicto, en consecuencia, lo que podemos rescatar es que dichos conflictos dan pie al cuestionamiento del sentido moral de cada personal y de cada sociedad y como resultado tenemos nuevas formas de ver las cosas y necesariamente de asignarles una valoración distinta a la ya dada.

\section{Trasmutación de la moral}

Como ya se ha mencionado en el capítulo anterior la moral en su aplicación se enfrenta a un sinfín de problemas, mismo que son el detonante para su transformación, y todo se inicia a través de un juicio moral, juicio que nos permite pronunciarnos sobre la bondad o la maldad de un acto, y que por cierto este juicio subjetivo puede caer en un relativismo moral como en el caso citado con antelación sobre la mentira, en la que en algunos casos puede ser de mayor utilidad, esto surge a partir del sentido moral que es el "conjunto de esquemas normas y reglas que hemos adquirido a través de nuestra educación familia y medio ambiente y que mantenemos en el momento de 
mantener un juicio moral" (Lazzarini, 2014), este sentido moral gira entorno de tres posiciones, el rechazo que se da cuando la norma no nos convence y bajo un razonamiento decidimos olvidarla, la indiferencia cuando la norma no nos dice nada y solo no la consideramos y por último la aceptación cuando al analizar la norma no convence de su validez y la hacemos parte de nuestro sentido moral.

Pues bien, esta posibilidad que tiene nuestro sentido moral da origen a lo que se a denominado transmutación de valores que no es otra cosa más que la evolución que nuestros esquemas morales han sufrido a través del tiempo, no obstante, algunas se mantienen, otras no tienen importancia y otras han desaparecido, así es como al emitir un juicio moral sustentado en nuestro sentido ético podemos demostrar que el juicio moral tiene un alto grado de transitoriedad, (Lazzarini, 2014), sobre el tema Nietzsche (2012) señala la necesidad de reemplazar los valores tradicionales (cristianos y burgueses)por una nueva tabla de valores centrados en vivir una vida plena.

Sustentado en lo anterior podemos señalar que esta transmutación de valores es un camino sin fin en la transformación de principios morales, dentro los cuales podemos citar algunos casos como la aprobación del aborto en Argentina durante el 2018, esto implica que el concepto moralista de la no suspensión del embarazo evoluciona a una aceptación, en lo que perece ser la entrega de la plena libertad a la mujer de decidir si quiere tener un hijo o no, en otro caso en Arabia
Saudita, país extremadamente patriarcal y religioso autorizaron que las mujeres puedan conducir, acción intolerable antes del decreto.

\section{Conclusión}

Como fue planteado la moral proviene del latín mos moris que significa costumbre y desde su origen se considera que es la forma en la que una persona se construye a través de las acciones que realiza día a día, por otro lado, la ética tiene su origen en el griego y es la ciencia que estudia a la moral.

Los principios morales surgieron como el medio de regular el comportamiento de los hombres en sociedad, normas que se van transformando de acuerdo a nuevas condiciones tanto educativas como culturales y sin lugar a duda a las exigencias de un mundo cada vez más globalizado que exige el pleno reconocimiento de los derechos humanos y de una plena equidad entre hombres y mujeres. Aún queda un considerable camino por recorrer ya que esta transmutación de valores tiene mucho que ver con el desarrollo económico, educativo y hasta de equilibrio de poder en todas las sociedades.

\section{Referencias bibliográficas}

Abad, J. J. (2009). Ética (1era ed.). (R. M. Campo, Ed.) Mèxico: McGraw-Hill. Recuperado el 20 de junio de 2018

De Zan, J. (2004). Conceptos de "Etica" y Moral. En J. d. Zan, La ética, los derechos y la justicia (págs. 19 - 21). Mexico: Konrad - adenauer. Recuperado el 23 de junio de 2018, de https://archivos.juridicas.unam.mx/www/bjv /libros/5/2228/4.pdf 
Dewey, J. (2008). Teoría de la Valoración. Scielo, 66, 263 - 266. Recuperado el 29 de junio de 2018, de https://scielo.conicyt.cl/scielo.php?script=sci _arttext\&pid=S0718-43602010000100016

Duarte, J., \& Sanchez, G. (2017). La mentira, una reivindicación moral. De como la mentira es útil en un paciente en etapa terminal. Scielo, 669 - 672. Recuperado el 30 de junio de 2018, de http://www.scielo.org.mx/pdf/mim/v33n5/0 186-4866-mim-33-05-668.pdf

Escobar, G. (2013). ÉTICA Introducción a su problematica y su historia (7ạ ed.). México: McGRAW-HILL. Recuperado el 4 de junio de 2018

Gutiérrez, R. (1998). Introducción a la ÉTICA (Undécima ed.). Mexico: Esfinge. Recuperado el 6 de junio de 2018, de https://es.scribd.com/document/166185693 /Introduccion-a-la-Etica-Raul-Gutierrez-Saenz

Lazzarini, R. (2014). El Juicio y la Argumentación moral. Scribd, 4 - 9. Recuperado el 30 de junio de 2018, de https://es.scribd.com/doc/6640811/Juiciosy-Argumentacion-Moral-Lanzarini

Manrique, T. (2006). La Ética Revolucionaria. (Scribp, Editor) Recuperado el 25 de junio de 2018, de https://es.scribd.com/document/47516340/L a-etica-revolucionaria-Trina-Manrique

Molina, N. (2013). La moral: ¿lnnata o adquirida? (U. E. Bosque, Ed.) Publicaciones Bioéticas, 8(1), 89 - 91. Recuperado el 29 de junio de 2018, de http://www.redalyc.org/pdf/1892/18922842 9007.pdf

Narváez, M. (2011). Estabilidad de reglas sociales e insuficiencia de rechazo. Telematica de Filosofía del Derecho(14), 7 - 24. Obtenido de http://www.rtfd.es/numero14/09-14.pdf

Nietzsche, F. (2012). Transmutacion de todos los valores. Filosofia al limit. Obtenido de https://sites.google.com/site/filosofiaallimit/ concepte-de-la-setmana/word-of-theweek/stuartmiillexplicadoporjohnskorupski

Ortiz, G. (2016). Sobre la distincion entre ética y moral. Scielo(45). Recuperado el 23 de junio de 2018, de http://www.scielo.org.mx/scielo.php?script= sci_arttext\&pid=S1405-02182016000200113

Palacios de la Torre, C. (2009). LA MORAL: UN CONCEPTO, MUCHAS INTERPRETACIONES. (J. C. M., Ed.) Contribuciones a las Ciencias Sociales. Recuperado el 23 de junio de 2018, de

http://www.eumed.net/rev/cccss/03/cpt.ht $\mathrm{m}$

Rodríguez, V., Frade, P., \& Albelo , L. M. (1996). Ética (7a ed.). Mexico: Alhambra. Recuperado el 30 de junio de 2018

Sánchez, A. J. (2006). Los valores éticos morales desde una perspectiva psicológica. Scielo, 6(3). Recuperado el 18 de junio de 2018, de http://scielo.sld.cu/scielo.php?script=sci_artt ext\&pid=S1727-81202006000300006

Torres, Z. (2014). Introducciòn a la ÉTICA (1a ed.). Mexico: Geupo Editorial Patria. Recuperado el 27 de junio de 2018, de https://books.google.com.mx/books?hl=es\&l $r=\& i d=y N T h B A A A Q B A J \& o i=f n d \& p g=P P 1 \& d q=$ $\% 22$ teoria+de+los+valores\%22\&ots=e99F26B _si\&sig=17uScUEWJEzAjMZ1wcaWK1Dqcl\#v=onepage\&q\&f=false 